\title{
Identification of Induction Motor Parameters in Industrial Drives with Artificial Neural Networks
}

\author{
Baburaj Karanayil, Muhammed Fazlur Rahman, and Colin Grantham \\ School of Electrical Engineering and Telecommunications, The University of New South Wales, Sydney NSW 2052, Australia \\ Correspondence should be addressed to Baburaj Karanayil, k.baburaj@unsw.edu.au
}

Received 3 June 2008; Revised 28 October 2008; Accepted 4 January 2009

Recommended by S. Paramasivam

\begin{abstract}
This paper presents a new method of online estimation of the stator and rotor resistance of the induction motor in the indirect vector-controlled drive, with artificial neural networks. The back propagation algorithm is used for training of the neural networks. The error between the rotor flux linkages based on a neural network model and a voltage model is back propagated to adjust the weights of the neural network model for the rotor resistance estimation. For the stator resistance estimation, the error between the measured stator current and the estimated stator current using neural network is back propagated to adjust the weights of the neural network. The performance of the stator and rotor resistance estimators and torque and flux responses of the drive, together with these estimators, is investigated with the help of simulations for variations in the stator and rotor resistance from their nominal values. Both types of resistance are estimated experimentally, using the proposed neural network in a vector-controlled induction motor drive. Data on tracking performances of these estimators are presented. With this approach, the rotor resistance estimation was found to be insensitive to the stator resistance variations both in simulation and experiment.
\end{abstract}

Copyright (C) 2009 Baburaj Karanayil et al. This is an open access article distributed under the Creative Commons Attribution License, which permits unrestricted use, distribution, and reproduction in any medium, provided the original work is properly cited.

\section{Introduction}

Indirect field oriented vector-controlled induction motor drives are widely used in industrial applications for highperformance drive systems. Because indirect field orientation utilizes an inherent slip relation, it is essentially a feedforward scheme and hence naturally parameter sensitive, particularly to the rotor resistance. A mismatch between the actual rotor flux and the estimated rotor flux leads to error between the actual motor torque and the estimated torque and hence leads to poor dynamic performance. The accuracy of the estimated rotor flux is greatly influenced by the value of rotor resistance $\left(R_{r}\right)$ used for control. Rotor resistance may vary up to $100 \%$ due to rotor heating, and recovering this information with a thermal model or a temperature sensor is not desirable. In addition, rotor resistance can change significantly with rotor frequency due to skew/proximity effect in machines with double-cage and deep-bar rotors. The problem related to stator and rotor resistance adaptation has been investigated by various authors [1-5].

Several methods have been reported to minimize the consequences of parameter sensitivity in indirect vector- controlled drives. The methods discussed in [6-8] are based on model reference adaptation of either flux or reactive power. The second approach, developed in $[9$, 10], was to compensate for rotor resistance variation by adaptive feedback linearization control with unknown rotor resistance. The third identification method is to detect the output signal variation invoked by the artificial injection signal [11]. Also, an extended Kalman filter was used for rotor resistance identification in $[12,13]$. These methods assumed that there is no change in the stator resistance during the rotor resistance estimation. To estimate stator resistance, online identification has been developed using model reference adaptation [14]. Combined stator and rotor resistance identification has been reported $[7,15]$. However, these methods are based on the assumption that the stator resistance does not change during the estimation of rotor resistance.

In this paper, online estimators are developed to address the situation of similar disturbances in both stator and rotor resistance simultaneously. Section 2 describes an online estimation of rotor resistance $\left(R_{r}\right)$ with multilayer feedforward artificial neural networks (ANNs) using online training 


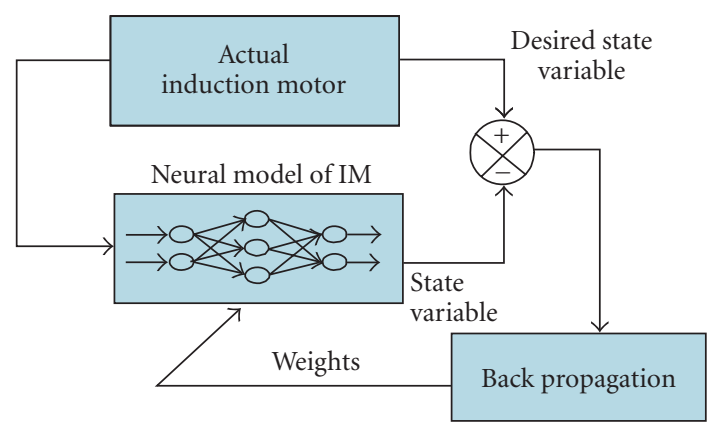

FIGURE 1: Parameter identification using neural networks.

[16]. Multilayer feedforward neural networks are regarded as universal approximations and have the capability to acquire nonlinear input-output relationships of a system by learning via the back propagation algorithm $[17,18]$. It should be possible that a simple two-layer feedforward neural network trained by the back propagation technique can be employed in the rotor resistance identification. In this estimator, two models of the state variable estimations can be used; one to provide the actual induction motor output states and the other to give the neural model output states. The total error between the desired and actual state variables may then be back propagated as shown in Figure 1, to adjust the weights of the neural model, so that the output of this model tracks the actual output. When the training is completed, the weights of the neural network should correspond to the parameters in the actual motor. However, the $R_{r}$ estimation algorithm requires the knowledge of stator resistance $\left(R_{s}\right)$ which may also vary up to $50 \%$ during operation. It has been observed that the error in $R_{s}$ leads to significant errors in $R_{r}$ estimation. It is hypothesized in this paper that the problem may be overcome by adding another online estimation for $R_{s}$ to the system using recurrent neural network, discussed in Section 3, giving the indirect vector control system, total immunity to both resistance variations. The proposed stator resistance observer was realized with a recurrent neural network trained using the standard back propagation learning algorithm. The recurrent neural network with feedback loops used in this paper is trained by standard back propagation algorithm. Such architecture is known to be a more desirable approach [19], and the implementation reported in this paper confirms this.

The rotor and stator resistance estimators described in Sections 2 and 3 are investigated by modeling studies using SIMULINK, and the results are discussed in Section 4 . The new resistance estimators are also tested in an experimental setup for both slip-ring and squirrel-cage induction motors. These results are discussed in detail in Section 5.

\section{Rotor Resistance Estimation Using Artificial Neural Networks}

The basic structure of an adaptive scheme described by Figure 1 is extended for rotor resistance estimation of an induction motor as illustrated in Figure 2. Two independent

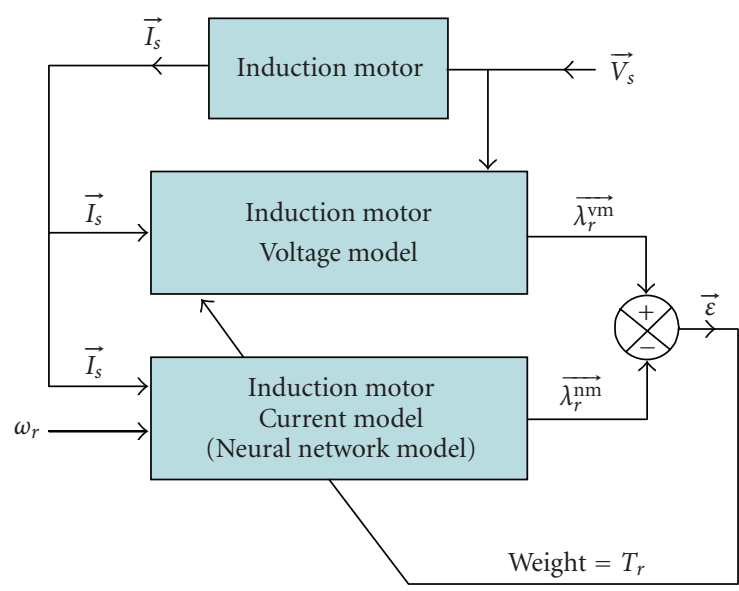

FIGURE 2: Structure of the neural network system for $R_{r}$ estimation.

observers are used to estimate the rotor flux vectors of the induction motor. Equation (1) is based on stator voltages and currents, and (2) is based on stator currents and rotor speed:

$$
\begin{gathered}
{\left[\begin{array}{c}
\frac{d \lambda_{d r}^{\mathrm{vm}}}{d t} \\
\frac{d \lambda_{q r}^{\mathrm{vm}}}{d t}
\end{array}\right]=\frac{L_{r}}{L_{m}}\left\{\left[\begin{array}{c}
v_{d s} \\
v_{q s}
\end{array}\right]-R_{s}\left[\begin{array}{c}
i_{d s} \\
i_{q s}
\end{array}\right]-\sigma L_{s}\left[\begin{array}{c}
\frac{d i_{d s}}{d t} \\
\frac{d i_{q s}}{d t}
\end{array}\right]\right\},} \\
{\left[\begin{array}{c}
\frac{d \lambda_{d r}^{\mathrm{im}}}{d t} \\
\frac{d \lambda_{q r}^{\mathrm{im}}}{d t}
\end{array}\right]=\left[\begin{array}{cc}
-\frac{1}{T_{r}} & -\omega_{r} \\
\omega_{r} & -\frac{1}{T_{r}}
\end{array}\right]\left[\begin{array}{l}
\lambda_{d r}^{\mathrm{im}} \\
\lambda_{q r}^{\mathrm{im}}
\end{array}\right]+\frac{L_{m}}{T_{r}}\left[\begin{array}{c}
i_{d s} \\
i_{q s}
\end{array}\right] .}
\end{gathered}
$$

The current model (2) can also be written as

$$
\dot{\overrightarrow{\lambda_{r}^{\mathrm{im}}}}=\left(\frac{-1}{T_{r}} I+\omega_{r} J\right) \overrightarrow{\lambda_{r}^{\mathrm{im}}}+\frac{L_{m}}{T_{r}} \overrightarrow{i_{s}},
$$

where

$$
\begin{array}{cc}
I=\left[\begin{array}{ll}
1 & 0 \\
0 & 1
\end{array}\right], & J=\left[\begin{array}{cc}
0 & -1 \\
1 & 0
\end{array}\right], \\
\overrightarrow{i_{s}}=\left[\begin{array}{l}
i_{d s} \\
i_{q s}
\end{array}\right], & \overrightarrow{v_{s}}=\left[\begin{array}{l}
v_{d s} \\
v_{q s}
\end{array}\right], \\
\overrightarrow{\lambda_{r}^{\mathrm{m}}}=\left[\begin{array}{l}
\lambda_{d r}^{\mathrm{im}} \\
\lambda_{q r}^{\mathrm{im}}
\end{array}\right], & \overrightarrow{\lambda_{r}^{\mathrm{vm}}}=\left[\begin{array}{l}
\lambda_{d r}^{\mathrm{vm}} \\
\lambda_{q r}^{\mathrm{vm}}
\end{array}\right] .
\end{array}
$$

The sample data model of (3) is shown as follows:

$$
\overrightarrow{\lambda_{r}^{\mathrm{nm}}}(k)=\left(W_{1} I+W_{2} J\right) \overrightarrow{\lambda_{r}^{\mathrm{nm}}}(k-1)+W_{3} \vec{i}_{s}(k-1),
$$

where

$$
W_{1}=1-\frac{T_{s}}{T_{r}} ; \quad W_{2}=\omega_{r} T_{s} ; \quad W_{3}=\frac{L_{m}}{T_{r}} T_{s} .
$$

Here, $T_{s}$ is the sampling period. Equation (5) can also be written as

$$
\overrightarrow{\lambda_{r}^{\mathrm{nm}}}(k)=W_{1} X_{1}+W_{2} X_{2}+W_{3} X_{3}
$$




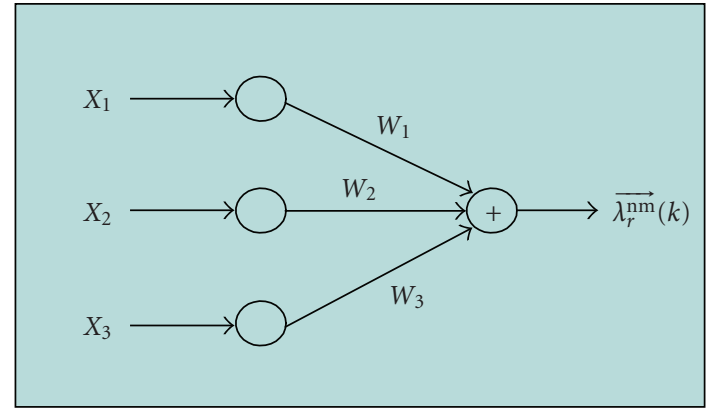

Figure 3: Two-layered neural network model.

where

$$
\begin{aligned}
& X_{1}=I \overrightarrow{\lambda_{r}^{\mathrm{nm}}}(k-1)=\left[\begin{array}{l}
\lambda_{d r}^{\mathrm{nm}}(k-1) \\
\lambda_{q r}^{\mathrm{nm}}(k-1)
\end{array}\right], \\
& X_{2}=J \overrightarrow{\lambda_{r}^{\mathrm{nm}}}(k-1)=\left[\begin{array}{c}
-\lambda_{q r}^{\mathrm{nm}}(k-1) \\
\lambda_{d r}^{\mathrm{nm}}(k-1)
\end{array}\right], \\
& X_{3}=I \overrightarrow{i_{s}}(k-1)=\left[\begin{array}{l}
i_{d s}(k-1) \\
i_{q s}(k-1)
\end{array}\right] .
\end{aligned}
$$

The neural network model represented by (7) is shown in Figure 3, where $W_{1}, W_{2}, W_{3}$ represent the weights of the networks, and $X_{1}, X_{2}, X_{3}$ are the three inputs to the network. If the network shown in Figure 3 is used to estimate $T_{r}, W_{2}$ is already known, and $W_{1}$ and $W_{3}$ need to be updated.

The weights of the network, $W_{1}$ and $W_{3}$ are found from training, so as to minimize the cumulative error function $E_{1}$,

$$
E_{1}=\frac{1}{2} \vec{\varepsilon}_{1}^{2}(k)=\frac{1}{2}\left\{\overrightarrow{\lambda_{r}^{\mathrm{vm}}}(k)-\overrightarrow{\lambda_{r}^{\mathrm{im}}}(k)\right\}^{2},
$$

and the weight adjustment using generalized delta rule is given by

$$
\Delta W_{1}(k)=\left[\overrightarrow{\lambda_{r}^{\mathrm{vm}}}(k)-\overrightarrow{\lambda_{r}^{\mathrm{nm}}}(k)\right]^{T} I \overrightarrow{\lambda_{r}^{\mathrm{nm}}}(k-1),
$$

where,

$$
\vec{\delta}=\frac{\partial E}{\partial \overrightarrow{\lambda_{r}^{\mathrm{nm}}}(k)}=\left[\overrightarrow{\lambda_{r}^{\mathrm{vm}}}(k)-\overrightarrow{\lambda_{r}^{\mathrm{nm}}}(k)\right]^{T}
$$

To accelerate the convergence of the error back propagation learning algorithm, the current weight adjustments are supplemented with a fraction of the most recent weight adjustment, as

$$
W_{1}(k)=W_{1}(k-1)-\eta_{1} \vec{\delta} X_{2}+\alpha_{1} \Delta W_{1}(k-1)
$$

where $\eta_{1}$ is the training coefficient, and $\alpha_{1}$ is a user-selected positive momentum constant.

Similarly, the changes in $W_{3}$ can be determined as follows:

$$
W_{3}(k)=W_{3}(k-1)-\eta_{1} \vec{\delta} X_{3}+\alpha_{1} \Delta W_{3}(k-1) .
$$

The rotor resistance $R_{r}$ can be calculated from either $W_{1}$ or $W_{3}$ from (14) or (15) as follows:

$$
\begin{aligned}
& R_{r}=\frac{L_{r} W_{3}}{L_{m} T_{s}}, \\
& R_{r}=\frac{L_{r}\left(1-W_{1}\right)}{T_{s}} .
\end{aligned}
$$

The rotor resistance estimator described in this section, has used the fluxes $\lambda_{d r}^{\mathrm{vm}}, \lambda_{q r}^{\mathrm{vm}}$ derived from the voltage model of the induction motor. This is dependent on stator resistance $R_{s}$ of the motor (see (1)). Modeling results in Section 4 clearly show that maximum possible variation in $R_{s}$ introduces a significant variation in $R_{r}$. In order to minimize the error in rotor resistance estimation, resulting from the stator resistance variation, an online stator resistance estimator is integrated, which is discussed in Section 3.

\section{Stator Resistance Estimation with Artificial Neural Networks}

The voltage and current model equations of the induction motor, (1) and (2) in Section 1, can also be written as

$$
\begin{aligned}
& \sigma L_{s} \frac{d i_{d s}}{d t}=\frac{L_{m}}{L_{r} T_{r}} \lambda_{d r}^{\mathrm{im}}+\frac{L_{m}}{L_{r}} \omega_{r} \lambda_{q r}^{\mathrm{im}}-\frac{L_{m}^{2}}{L_{r} T_{r}} i_{d s}+V_{d s}-R_{s} i_{d s}, \\
& \sigma L_{s} \frac{d i_{q s}}{d t}=\frac{L_{m}}{L_{r} T_{r}} \lambda_{q r}^{\mathrm{im}}-\frac{L_{m}}{L_{r}} \omega_{r} \lambda_{d r}^{\mathrm{im}}-\frac{L_{m}^{2}}{L_{r} T_{r}} i_{q s}+V_{q s}-R_{s} i_{q s} .
\end{aligned}
$$

Using the discrete form of (16),

$i_{d s}^{*}(k)=W_{4} i_{d s}^{*}(k-1)+W_{5} \lambda_{d r}^{\mathrm{im}}(k)+W_{6} \omega_{r} \lambda_{q r}^{\mathrm{im}}(k)+W_{7} V_{d s}(k)$,

where

$$
\begin{gathered}
W_{4}=1-\frac{T_{s}}{\sigma L_{s}} \frac{L_{m}^{2}}{L_{r} T_{r}}-\frac{T_{s}}{\sigma L_{s}} R_{s}, \\
W_{5}=\frac{T_{s}}{\sigma L_{s}} \frac{L_{m}}{L_{r} T_{r}}, \\
W_{6}=\frac{T_{s}}{\sigma L_{s}} \frac{L_{m}}{L_{r}} \omega_{r}, \\
W_{7}=\frac{T_{s}}{\sigma L_{s}} .
\end{gathered}
$$

The weights $W_{5}, W_{6}$, and $W_{7}$, are calculated from the motor parameters, motor speed $\omega_{r}$, and the sampling interval $T_{s}$.

To examine the effect of stator resistance variation in the amplitude of stator current, modeling studies were carried out with a ramp change in stator resistance. The stator current profile is shown in Figure 4. The relationship between stator current and stator resistance is nonlinear which could be easily mapped using a neural network.

Equation (18) can be represented by a recurrent neural network as shown in Figure 5. The standard backpropagation learning rule is then employed to train the 


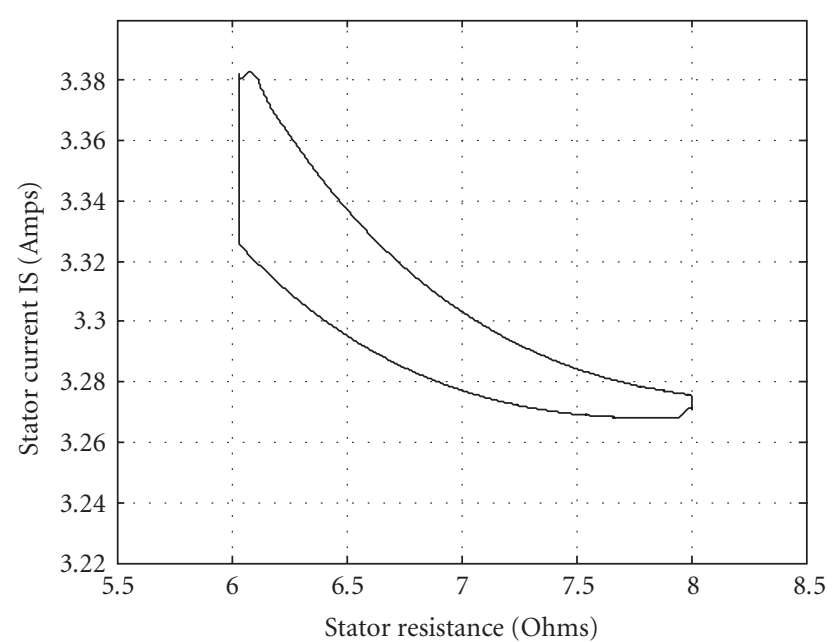

FIgURE 4: Relationship between $R_{s}$ variation with amplitude of stator current.

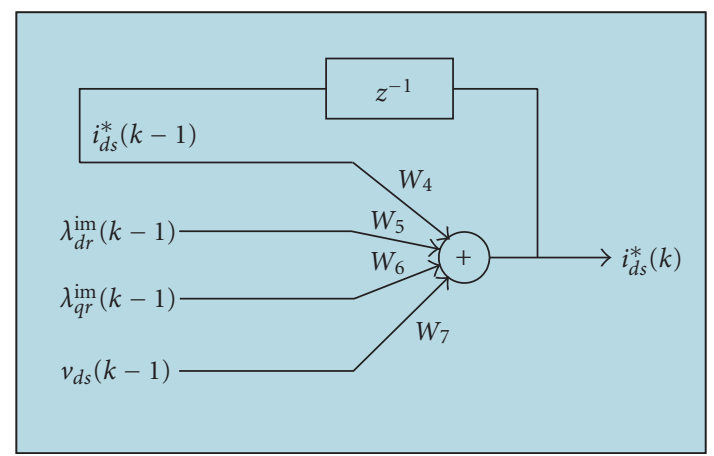

Figure 5: $D$-axis stator current estimation using recurrent neural network based on (18).

network. The weight $W_{4}$ is the result of training so as to minimize the cumulative error function $E_{2}$ :

$$
E_{2}=\frac{1}{2} \overrightarrow{\varepsilon_{2}^{2}}(k)=\frac{1}{2}\left\{i_{d s}(k)-i_{d s}^{*}(k)\right\}^{2} .
$$

The weight adjustment for $W_{4}$ is given by

$$
\Delta W_{4}(k) \alpha\left[i_{d s}(k)-i_{d s}^{*}(k)\right] i_{d s}^{*}(k-1) .
$$

To accelerate the convergence of the error back propagation learning algorithm, the current weight adjustments are supplemented with a fraction of the most recent weight adjustment, as in

$$
W_{4}(k)=W_{4}(k-1)+\eta_{2} \Delta W_{4}(k)+\alpha_{2} \Delta W_{4}(k-1),
$$

where $\eta_{2}$ is the training coefficient, $\alpha_{2}$ is a user-selected positive momentum constant.

Similarly, using the discrete form of (17),

$$
i_{q s}^{*}(k)=W_{4} i_{q s}(k-1)+W_{5} \lambda_{q r}^{\mathrm{im}}(k)-\omega_{r} W_{6} \lambda_{d r}^{\mathrm{im}}(k)+W_{7} V_{q s}(k) .
$$

Equation (23) can be represented by a neural network as shown in Figure 6.

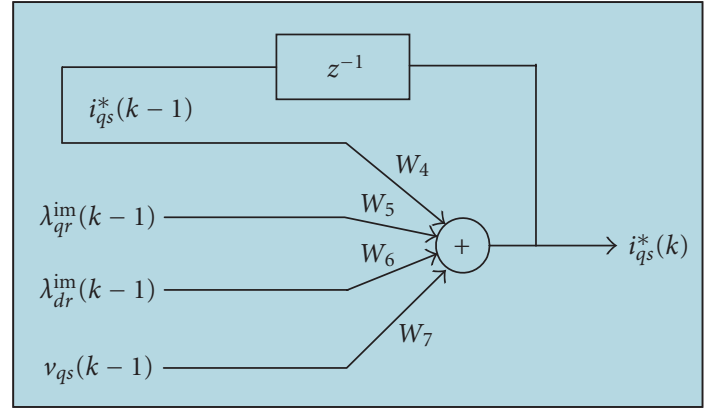

Figure 6: Q-axis stator current estimation using recurrent neural network based on (23).

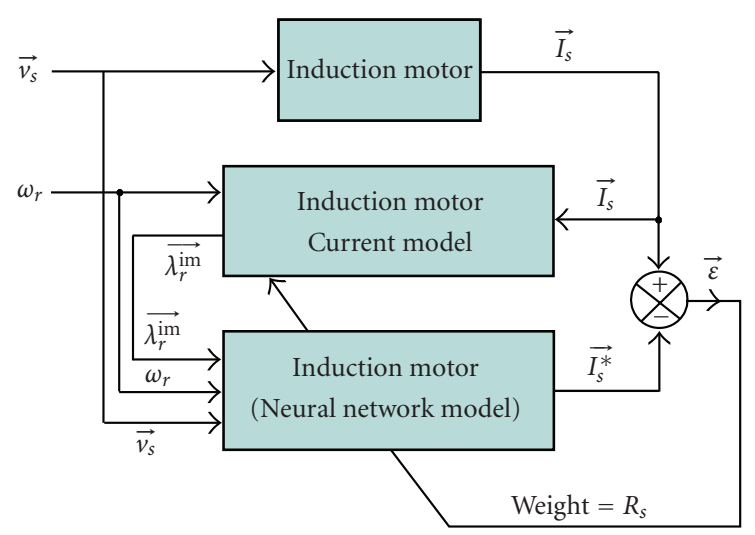

FIgURe 7: $R_{s}$ estimation using artificial neural network.

The weight $W_{4}$ is adjusted with training based on (22).

The stator resistance $R_{s}$ can be calculated from

$$
\hat{R}_{s}=\left\{1-W_{4}-\frac{T_{s}}{\sigma L_{s}} \frac{L_{m}^{2} \hat{R}_{r}}{L_{r}{ }^{2}}\right\} \frac{\sigma L_{s}}{T_{s}} .
$$

The stator resistance of an induction motor can be thus estimated from the stator current using the neural network system as indicated in Figure 7.

\section{Modelling Results}

The block diagram of a rotor flux oriented induction motor drive, together with both stator and rotor resistance identifications, is shown in Figure 8. The use of artificial neural networks in identification algorithms in Sections 2 and 3 is verified by simulations with the aid of SIMULINK.

In order to investigate the performance of the drive for parameter variations in rotor resistance $R_{r}$, a series of simulations were conducted by introducing error between the actual value $R_{r \text {-motor }}$ and the value used in the controller $R_{r \text {-control }}$ Similarly, another series of simulations were conducted by introducing error between the actual stator resistance $R_{s \text {-motor }}$ and the one used in the controller $R_{s \text {-control }}$. All these investigations were conducted for the drive running at $1000 \mathrm{rev} /$ minute and a constant load torque of $7.4 \mathrm{Nm}$. The parameters of the motor used for modeling studies are in Table 1. 


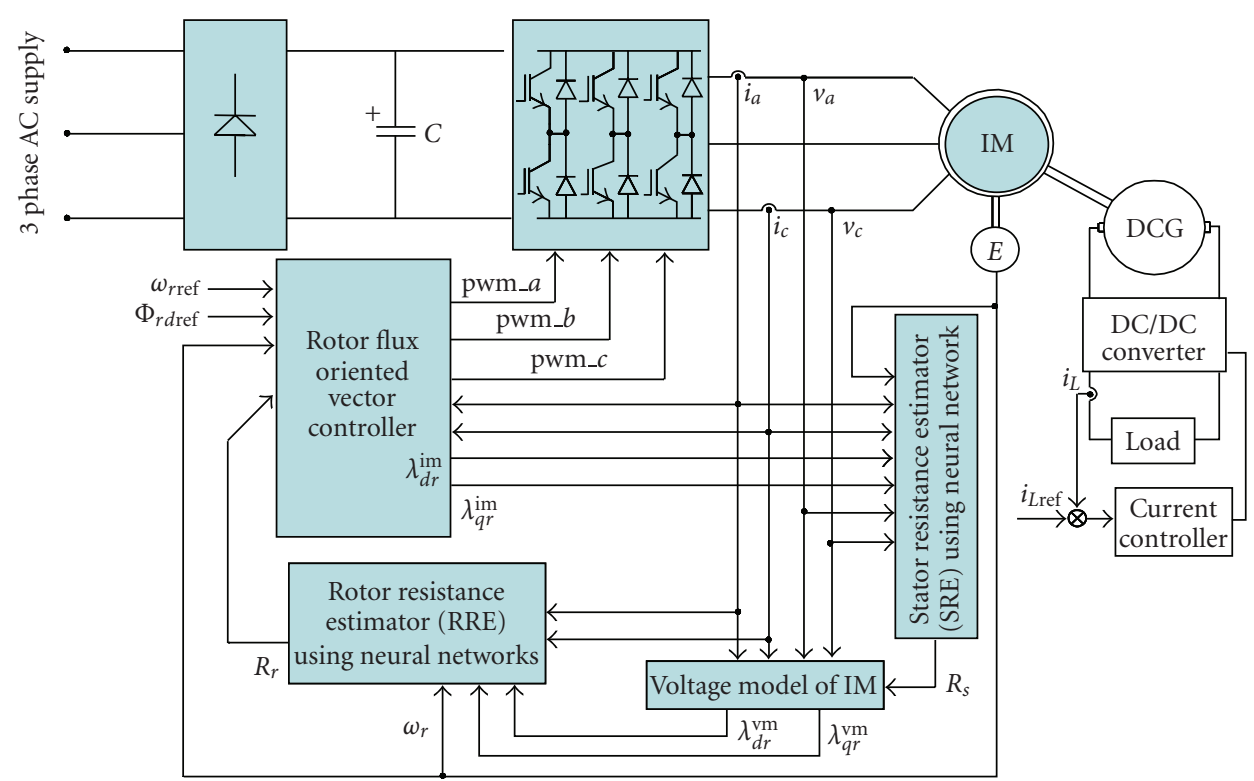

FIGURE 8: Schematic of the indirect vector-controlled induction motor drive with online stator and rotor resistance tracking.

(i)

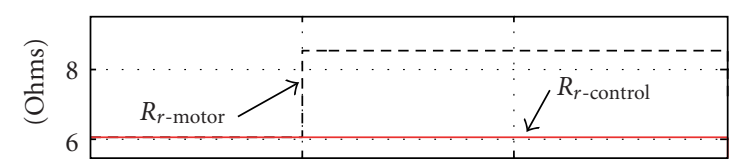

(ii)

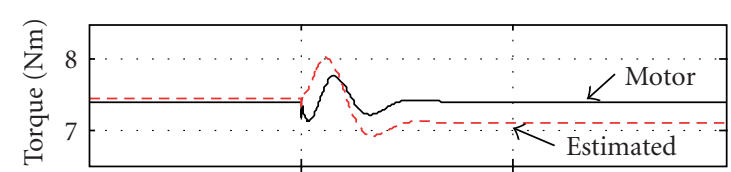

(iii)

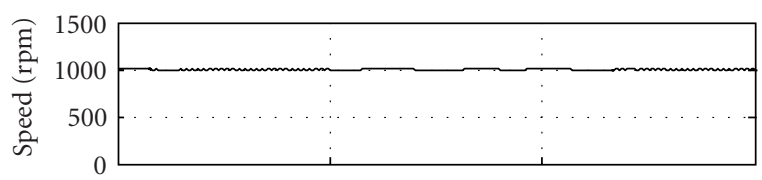

(iv)

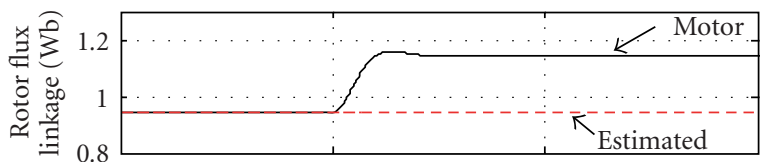

(v)

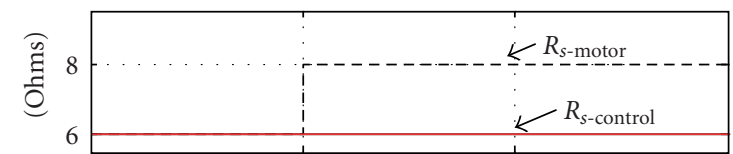

(vi)

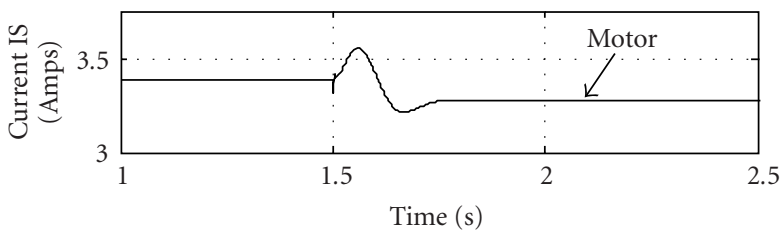

(a) $40 \%$ step change in $R_{r \text {-motor }}$ and $R_{s \text {-motor }}, R_{s \text {-motor }}$ and $R_{s \text {-control }}$ uncompensated (i)

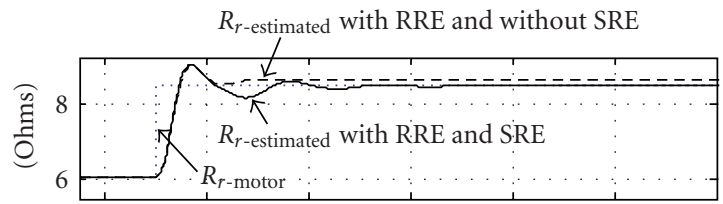

(ii)

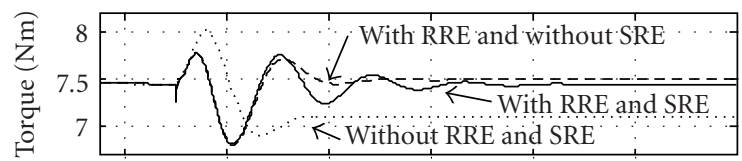

(iii)

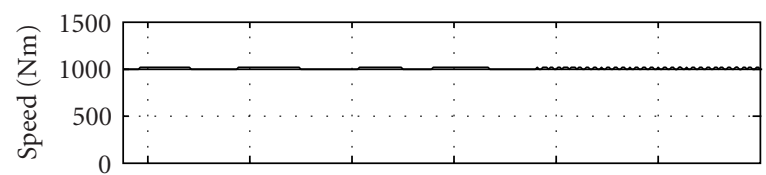

(iv)

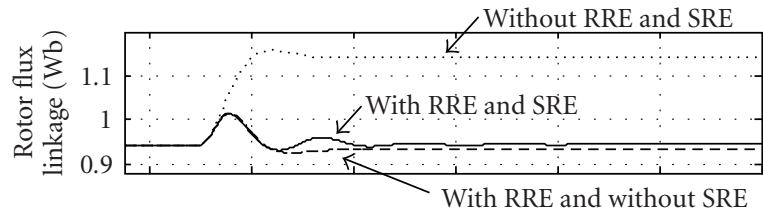

(v)

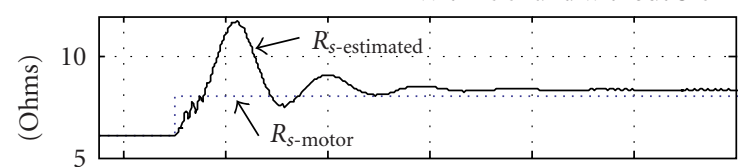

(vi)

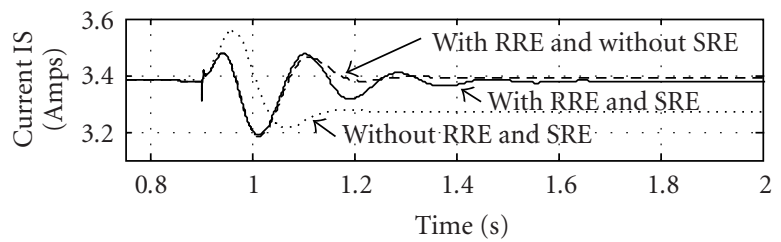

(b) $40 \%$ step change in $R_{r \text {-motor }}$ and $R_{s \text {-motor }}, R_{s \text {-motor }}$ and $R_{s \text {-control }}$ compensated

FIgURE 9: Performance of the drive with and without rotor and stator resistance compensations. 
TABLE 1: Induction motor parameters.

$1.1 \mathrm{~kW}, 1415 \mathrm{RPM}, 415 \mathrm{~V}, 2.77 \mathrm{~A}, 3$ phases, 4 pole, $50 \mathrm{~Hz}$
Stator resistance $R_{s}: 6.03 \Omega$
Rotor leakage inductance $L_{\mathrm{rs}}: 29.9 \mathrm{mH}$
Stator leakage inductance $L_{\mathrm{ls}}: 29.9 \mathrm{mH}$
Magnetizing inductance $L_{m}: 489.3 \mathrm{mH}$
Rotor resistance $R_{r}: 6.085 \Omega$ at $50 \mathrm{~Hz}$
Moment of inertia $J_{T}: 0.011787 \mathrm{kgm}^{2}$

Initially, a $40 \%$ error was introduced between $R_{r \text {-motor }}$ and $R_{r \text {-control }}$ and $R_{s \text {-motor }}$ and $R_{s \text {-control simultaneously at }}$ 1.5 seconds, after switching off both the rotor resistance estimation (RRE) and stator resistance estimation (SRE) blocks in Figure 8 . The steady-state values of the torque, rotor flux linkage, and the amplitude of the stator current vector are shown in Figure 9(a). The rotor flux linkage in the motor increases by $21 \%$ compared to its estimated value, when the error in rotor resistance is introduced, as shown in Figure 9(a) (iv). The estimated torque is $4 \%$ lower than the actual motor torque, as shown in Figure 9(a) (ii). Also, there is a $3.25 \%$ drop in the amplitude of the stator current vector starting at 1.5 seconds, when the error is introduced, as in Figure 9(a) (vi).

Later, simulations were repeated after switching on only the rotor resistance estimation block with the SRE block switched off, for the same errors introduced in Figure 9(a). The estimated $R_{r}$, in this case, is higher than the $R_{r \text {-motor }}$ by $1.7 \%$ as shown in Figure 9(b) (i). The estimated torque is $1.35 \%$ higher than the real motor torque, as shown in Figure 9(b) (ii). But the estimated rotor flux linkage is 1.5\% lower than the actual rotor flux linkage as indicated in Figure 9(b) (iv). The stator current amplitude increases only by $0.4 \%$ in this case, as shown in Figure 9(b) (vi).

Finally, the simulations were carried out with both the RRE and SRE blocks switched on. The results of torque, rotor flux linkage, and stator current amplitude are shown for both of the cases, in Figure 9(b). The errors reported in the previous paragraph, between estimated and real quantities of torque rotor flux linkage and stator current amplitude, have largely disappeared in this case. The estimated rotor resistance has tracked the real rotor resistance of the motor very well, as the estimation error now drops to $0.3 \%$ as in Figure 9(b) (i).

However, there was a small but insignificant error of $4.4 \%$, as shown Figure 9(b) (v), for the estimated stator resistance with respect to the real stator resistance.

The Figures 9(a) and 9(b) also described the possible steady-state errors encountered in a situation, where a step change in resistance is applied, only for the purpose of investigation. However, the practical variation in resistance is very slow, and a corresponding analysis is also carried out, and the results are indicated in Figure 10. The simulations are done in three steps. At first, the drive system is analyzed after introducing error between $R_{r \text {-motor }}$ and $R_{r \text {-control }}$ and $R_{s-\text { motor }}$ and $R_{s \text {-control }}$ keeping both RRE and SRE turned OFF. Repeated simulations were also carried out, with RRE ON (i)

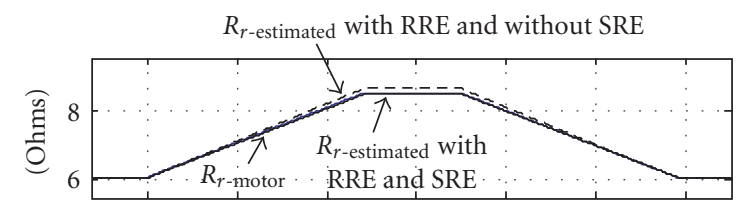

(ii)

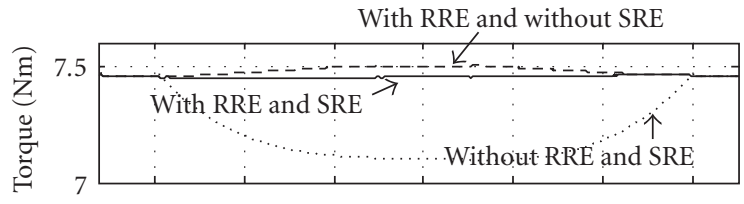

(iii)

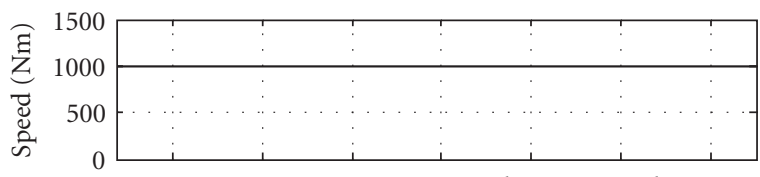

(iv)

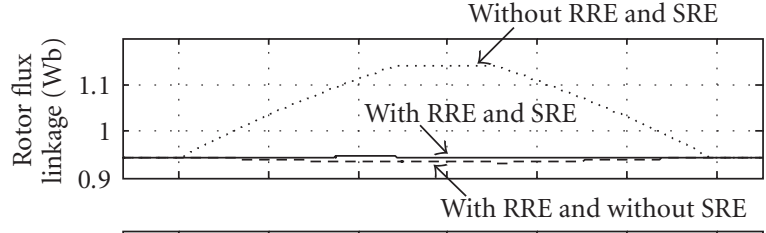

(v)

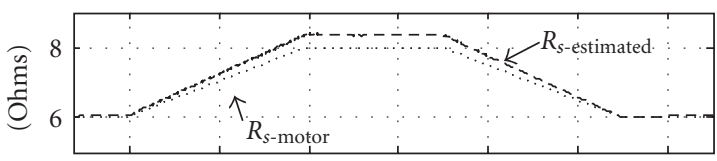

With RRE and without SRE

(vi)

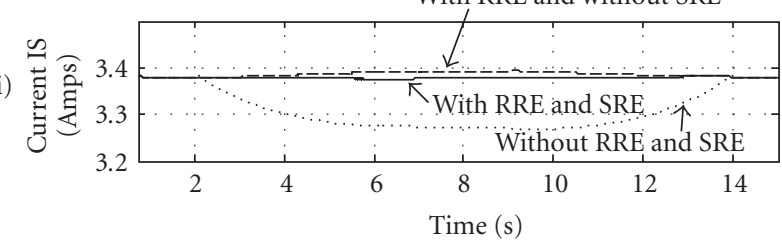

Figure 10: Performance of the induction motor drive with a ramp change in stator and rotor resistance with and without RRE and SRE.

and SRE OFF. The estimated $R_{r}$, in this case, is higher than the $R_{r \text {-motor }}$ by $1.1 \%$ as shown in Figure 10 (i). The estimated torque is $1.3 \%$ higher than the real motor torque, as shown in Figure 10 (ii). But the estimated rotor flux linkage is $1.5 \%$ lower than the actual rotor flux linkage as indicated in Figure 10 (iv). The stator current amplitude increases only by $0.4 \%$ in this case, as shown in Figure 10 (vi).

Finally, both rotor and stator resistance estimators are investigated with both RRE and SRE switched ON. The estimated rotor resistance has tracked the real rotor resistance of the motor very well, as the error now drops to $0.3 \%$ as in Figure 10 (i). However, there was a small but insignificant error of 5\%, as shown Figure 10 (v), for the estimated stator resistance with respect to the real stator resistance. But its effect on the rotor flux oriented control is negligible, as the errors between torques, rotor flux linkages, and stator current amplitudes are virtually eliminated.

\section{Experimental Results}

In order to verify the proposed stator and rotor resistance estimation algorithms, a rotor flux oriented induction motor 


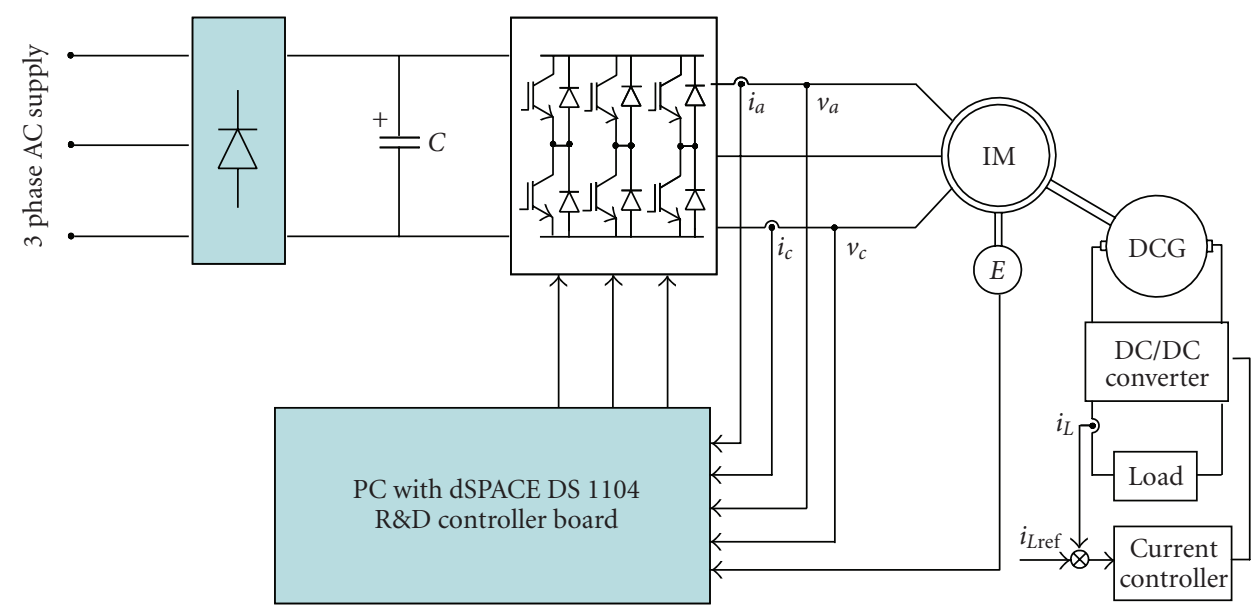

FIGURE 11: Experimental setup for the resistance identification in induction motor drive.

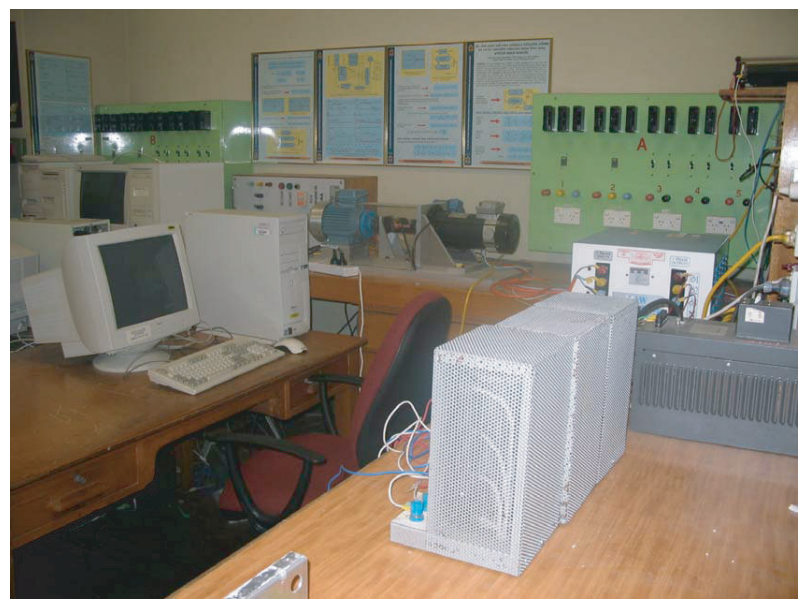

FIgURE 12: Photograph of the experimental setup of the $1.1 \mathrm{~kW}$ squirrel cage induction motor drive.

drive was implemented in the laboratory as shown in Figure 11.

The experimental setup was built for the $1.1 \mathrm{~kW}$ squirrel cage induction motor around a dSPACE DS1104 controller board residing in PC, as shown in Figure 12. An IGBT inverter with a switching frequency of $5 \mathrm{kHz}$ was used for driving the induction motor. Hand-coded $\mathrm{C}$ programs with the real-time reference library functions were used to develop the control programs. The current and flux controllers were implemented with 100 microsecond sampling interval and the speed controller with 500 microsecond. The proposed rotor resistance estimation block used 1000 microsecond sampling time, and the stator resistance estimation block used $100 \mu$ microsecond. An encoder with 5000 pulses per revolution was used for position and speed feedbacks. A permanent magnet DC motor coupled to the induction motor was used to load the induction motor. A constant load torque was maintained by using the current control loop in the load circuit.

5.1. Results for Slip Ring Induction Motor. The induction motor in Table 1 is of squirrel cage type, and its rotor

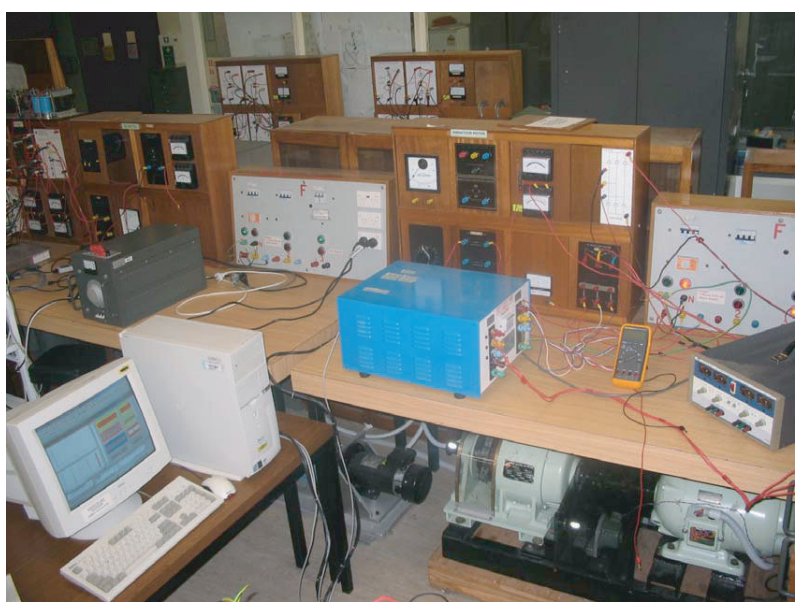

FIGURE 13: Photograph of the experimental setup of the $3.7 \mathrm{~kW}$ slipring induction motor drive.

resistance measurement with a dc current measurement is not possible, the initial rotor resistance estimation experiment was conducted on a slip ring induction motor with specifications in Table 2. The experimental setup for the $3.7 \mathrm{~kW}$ slip-ring induction motor is shown in Figure 13. A separately excited DC motor coupled to the induction motor was used to load the induction motor. The estimated rotor resistance was noted using the estimation principles described in Sections 2 and 3, when the motor was running at $1000 \mathrm{rev} / \mathrm{min}$ and drawing $75 \%$ of full load current. The drive was shut down, and the rotor resistance was measured immediately, using a dc current injection. Both the estimated and measured rotor resistance of this motor are shown in Table 3.

5.2. Results for Squirrel Cage Induction Motor. After establishing the validity of the proposed rotor resistance estimation with the slip-ring induction motor, experimental investigations are repeated with the squirrel cage induction motor which was used for the modeling studies.

In order to examine the capability of tracking the rotor resistance of the induction motor with the proposed 


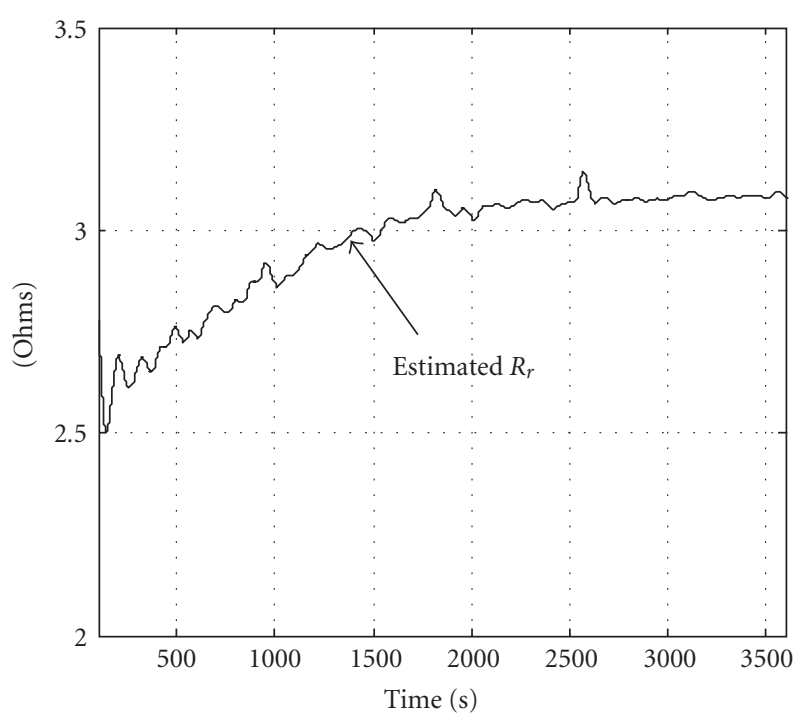

Figure 14: Estimated $R_{r}$ in experiment.

TABLE 2: Induction motor parameters.

$3.7 \mathrm{~kW}, 1410 \mathrm{RPM}, 415 \mathrm{~V}, 7.8 \mathrm{~A}, 3$ phases, 4 pole, $50 \mathrm{~Hz}$

Stator resistance $R_{s}=1.54 \Omega$

Stator leakage inductance $L_{\mathrm{ls}}=11.65 \mathrm{mH}$

Rotor leakage inductance $L_{\mathrm{rs}}=11.65 \mathrm{mH}$

Magnetizing inductance $L_{m}=184.61 \mathrm{mH}$

Rotor resistance $R_{r}=2.62 \Omega$

Moment of inertia $J_{T}=0.08 \mathrm{kgm}^{2}$

TABLE 3: Rotor resistance measurements.

\begin{tabular}{ll}
\hline Measured rotor resistance & $\begin{array}{l}\text { Estimated rotor resistance using } \\
\text { the proposed estimator }\end{array}$ \\
\hline $2.62 \Omega$ & $2.51 \Omega$ \\
\hline
\end{tabular}

estimator, a temperature rise test was conducted, at a motor speed of $1000 \mathrm{rev} / \mathrm{min}$. The results of $R_{r}$ estimation obtained from the experiment are shown in Figure 14, after logging the data for 60 minutes. Figure 15 shows the $d$-axis rotor flux linkages of the current model $\left(\lambda_{d r}^{\mathrm{im}}\right)$, the voltage model $\left(\lambda_{d r}^{\mathrm{vm}}\right)$, and the neural model $\left(\lambda_{d r}^{\mathrm{nm}}\right)$, taken at the end of heat run. All of the flux linkages are in the stationary reference frame. The flux linkages $\lambda_{d r}^{\mathrm{im}}$ and $\lambda_{d r}^{\mathrm{vm}}$ are updated with a sampling time of 100 microseconds, whereas the flux $\lambda_{d r}^{\mathrm{nm}}$ is updated only at 1000 microseconds. The flux linkage $\lambda_{d r}^{\mathrm{nm}}$ follows the flux linkage $\lambda_{d r}^{\mathrm{vm}}$ due to the online training of the neural network. The coefficients used for training are $\eta_{1}=0.005$ and $\alpha_{1}=$ $10.0 e-6$.

To test the stator resistance estimation, an additional $3.4 \Omega$ per phase was added in series with the induction motor stator, with the motor running at $1000 \mathrm{rev} / \mathrm{min}$ with a load torque of $7.4 \mathrm{Nm}$. The estimated stator resistance together with the actual stator resistance is shown in Figure 16. The estimated stator resistance converges to $9.4 \Omega$ within less than 200 milliseconds. Figure 17 shows both the measured $d$-axis stator current and the one estimated by the neural network

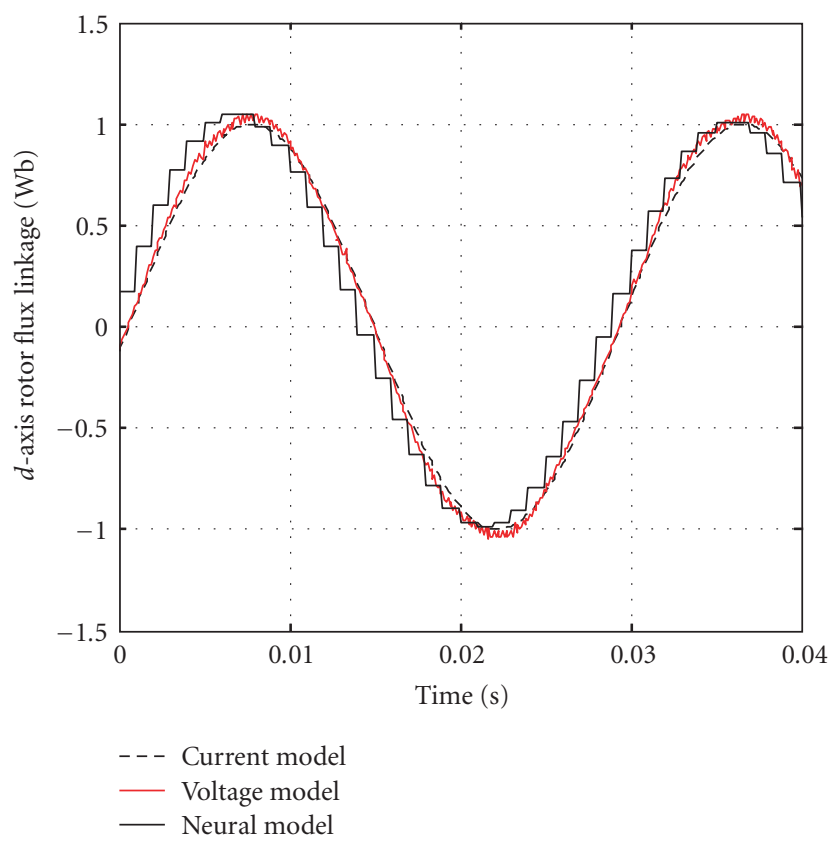

FIgURE 15: Rotor fluxes in $R_{r}$ estimation.

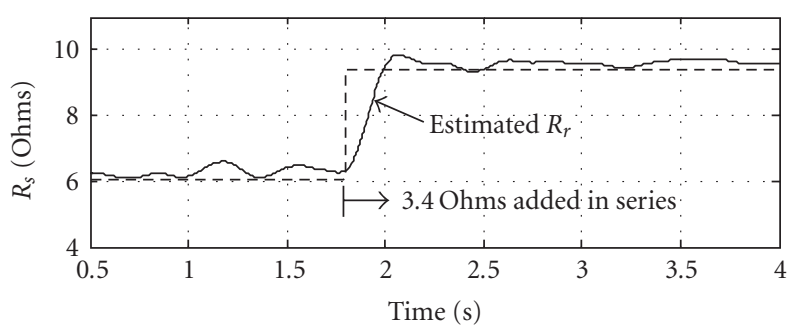

(a)

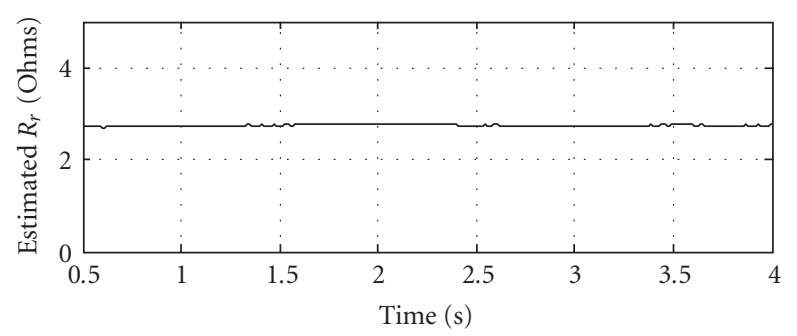

(b)

FIGURE 16: Estimated stator resistance $R_{s}$ in experiment.

model. The neural model output $i_{d s}^{*}(k)$ follows the measured values $i_{d s}(k)$ due to the online training of the network. The neural model current estimate is updated with a sampling time of 100 microseconds. The coefficients used for training are $\eta_{2}=0.00216$ and $\alpha_{2}=10.0 e-6$.

\section{Analysis of Results}

The modeling results as described in Figure 9(b) indicate that the proposed rotor and stator resistance estimators can converge in a short time, as low as 200 milliseconds 


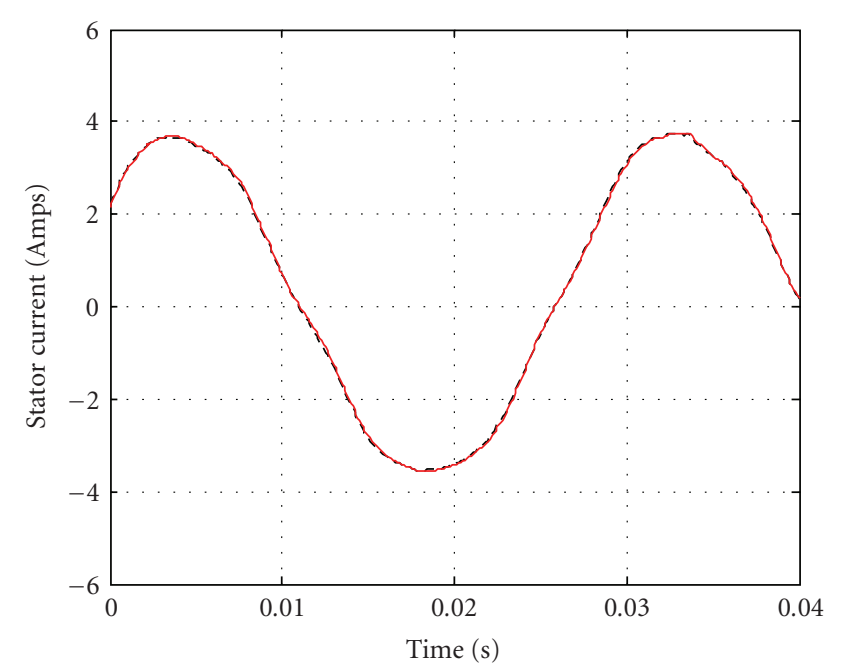

_ Estimated by neural network

- - - Measured

FIgURE 17: Stator currents in $R_{s}$ estimation.

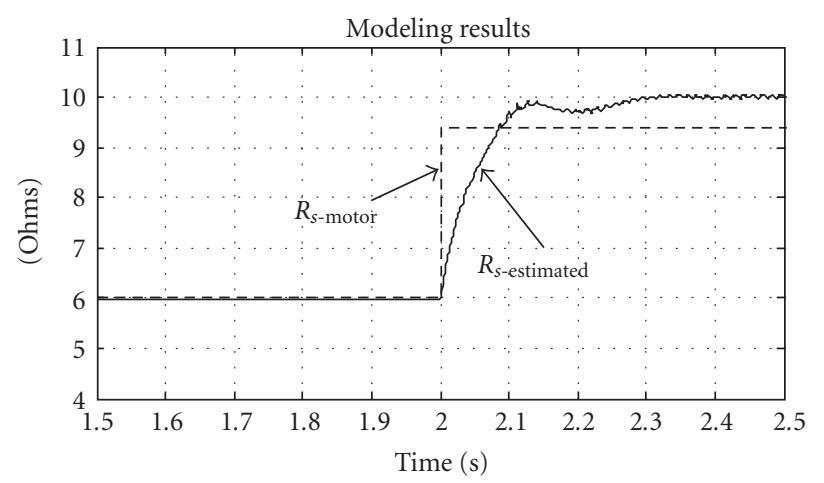

(a)

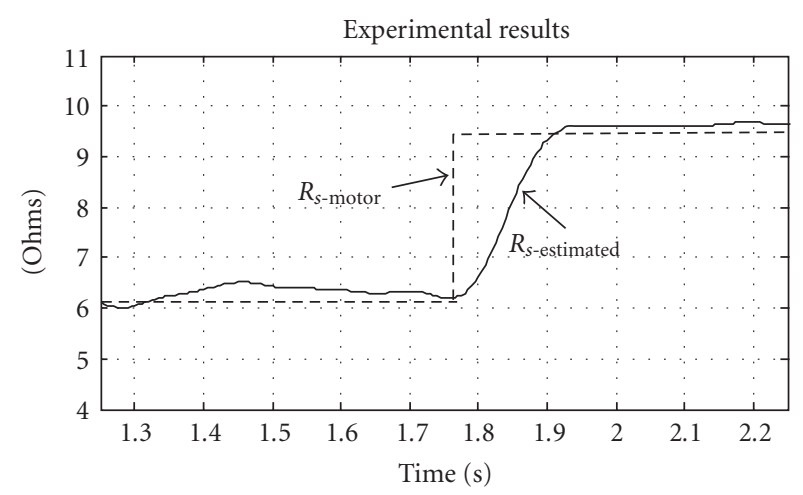

(b)

FIGURE 18: Comparison of stator resistance estimations.

corresponding to a $40 \%$ step change for both stator and rotor resistance simultaneously. In order to compare the stator resistance estimation for simulation and experiment, simulation is repeated with SRE and RRE blocks in Figure 8.

Then, a step change in $R_{s-\text { motor }}$ is applied without a step change in $R_{r \text {-motor }}$, and the results are recorded as the upper trace in Figure 18. The bottom trace in this figure is the same as the top trace of Figure 16. The estimation time in modeling is in very close agreement with that obtained from experiment.

\section{Conclusions}

This paper has presented a new online estimation technique for the rotor resistance $R_{r}$ in the presence of $R_{s}$ variations for the induction motor drive. The $R_{r}$ estimation was found to be totally insensitive to $R_{s}$ variations, as a result of the stator resistance estimation which is embedded separately.

Investigations carried out in this paper have clearly shown that two ANNs can be used in estimating $R_{r}$ in the face of significant variations in $R_{s}$, which can occur due to motor heating. Both the rotor and stator resistance variations can be successfully estimated using the adaptation capabilities of neural networks. The implementation of these techniques required only a small increase of the computation times. The feasibility and validity of the proposed identification have been proved by the excellent experimental results.

\section{Nomenclatures}

$v_{d s}, v_{q s}:$
$\vec{v}_{s}:$
$i_{d s}, i_{q s}:$
IS:

$i_{d s}^{*}, i_{q s}^{*}:$

$\overrightarrow{i_{s}} \overrightarrow{i_{s}^{*}}:$

$\lambda_{d r}^{\mathrm{vm}}, \lambda_{q r}^{\mathrm{vm}}$

$\lambda_{d r}^{\mathrm{im}}, \lambda_{q r}^{\mathrm{im}}$

$\lambda_{d r}^{\mathrm{nm}}, \lambda_{q r}^{\mathrm{nm}}:$

$R_{s}, R_{r}$ :

$W_{1}, W_{2}, W_{3}$ : $d(q)$-axis stator voltages in stator reference frame

Stator voltage vector in stator reference frame

$d(q)$ stator currents in stator reference frame

Magnitude of the stator current $\operatorname{vector}\left(\sqrt{i_{d s}^{2}+i_{q s}^{2}}\right)$

$d(q)$ stator current estimates in stator reference frame

Stator current vector in stator reference frame Rotor flux linkages estimated by voltage model in stator reference frame

Rotor flux linkages estimated by current model in stator reference frame Rotor flux linkages estimated by neural network Stator(rotor) resistance

$W_{4}, W_{5}, W_{6}, W_{7}$ : Neural network weights in stator resistance estimator

$E_{1}, E_{2}$ :

$\eta_{1}, \eta_{2}$ :

$\alpha_{1}, \alpha_{2}$ :

$\vec{\varepsilon}$ :

$\varepsilon_{1}, \varepsilon_{2}$ :

$\omega_{r}$ : Cumulative error fuctions Training coefficients Momentum constants Error function vector Error functions Rotor speed in rev/minute. 


\section{References}

[1] R. Krishnan and A. S. Bharadwaj, "A review of parameter sensitivity and adaptation in indirect vector controlled induction motor drive systems," IEEE Transactions on Power Electronics, vol. 6, no. 4, pp. 695-703, 1991.

[2] R. D. Lorenz, "A simplified approach to continuous online tuning of field-oriented induction machine drives," IEEE Transactions on Industry Applications, vol. 26, no. 3, pp. 420 424, 1990.

[3] T. Rowan, R. Kerkman, and D. Leggate, "A simple online adaption for indirect field orientation of an induction machine," IEEE Transactions on Industry Applications, vol. 27, no. 4, pp. 720-727, 1991.

[4] C. C. Chan and H. Wang, "An effective method for rotor resistance identification for high-performance induction motor vector control," IEEE Transactions on Industrial Electronics, vol. 37, no. 6, pp. 477-482, 1990.

[5] J. Holtz and T. Thimm, "Identification of the machine parameters in a vector-controlled induction motor drive," IEEE Transactions on Industry Applications, vol. 27, no. 6, pp. 1111-1118, 1991.

[6] H. Sugimoto and S. Tamai, "Secondary resistance identification of an induction motor applied model reference adaptive system and its characteristics," in Proceedings of the IEEE/IAS Annual Meeting Conference, pp. 613-620, Toronto, Canada, October 1985.

[7] L. Zhen and L. Xu, "A mutual MRAS identification scheme for position sensorless fieldorientation control of induction machines," in Proceedings of the 30th IAS Annual Meeting on Industry Applications Conference (IAS '95), vol. 1, pp. 159-165, Orlando, Fla, USA, October 1995.

[8] T. Noguchi, S. Kondo, and I. Takahashi, "Field-oriented control of an induction motor with robust on-line tuning of its parameters," IEEE Transactions on Industry Applications, vol. 33, no. 1, pp. 35-42, 1997.

[9] R. Marino, S. Peresada, and P. Valigi, "Adaptive input-output linearizing control of induction motors," IEEE Transactions on Automatic Control, vol. 38, no. 2, pp. 208-221, 1993.

[10] R. Marino, S. Peresada, and P. Tomei, "Global adaptive output feedback control of induction motors with uncertain rotor resistance," IEEE Transactions on Automatic Control, vol. 44, no. 5, pp. 967-983, 1999.

[11] T. Matsuo and T. A. Lipo, "A rotor parameter identification scheme for vector-controlled induction motor drives," IEEE Transactions on Industry Applications, vol. 21, no. 3, pp. 624632, 1985.

[12] L. C. Zai and T. A. Lipo, "An extended Kalman filter approach to rotor-time constant measurement in PWM induction motor drives," in Proceedings of the 22nd IEEE Industry Applications Society Annual Meeting, vol. 1, pp. 177-183, Atlanta, Ga, USA, October 1987.

[13] D. Atkinson, P. Acarnley, and J. Finch, "Observers for induction motor state and parameter estimation," IEEE Transactions on Industry Applications, vol. 27, no. 6, pp. 1119-1127, 1991.

[14] R. J. Kerkman, B. J. Seibel, T. M. Rowan, and D. Schlegel, "A new flux and stator resistance identifier for AC drive systems," in Proceedings of the 30th IAS Annual Meeting on Industry Applications Conference (IAS '95), vol. 1, pp. 310-318, Orlando, Fla, USA, October 1995.

[15] T. G. Habetler, F. Profumo, G. Griva, M. Pastorelli, and A. Bettini, "Stator resistance tuning in a stator-flux field-oriented drive using an instantaneous hybrid flux estimator," IEEE Transactions on Power Electronics, vol. 13, no. 1, pp. 125-133, 1998.

[16] B. Karanayil, M. F. Rahman, and C. Grantham, "Rotor resistance identification using artificial neural networks for an indirect vector controlled induction motor drive," in Proceedings of the 27th Annual Conference of the IEEE Industrial Electronics Society (IECON '01), vol. 2, pp. 1315-1320, Denver, Colo, USA, November-December 2001.

[17] K.-I. Funahashi, "On the approximate realization of continuous mappings by neural networks," Neural Networks, vol. 2, no. 3, pp. 183-192, 1989.

[18] K. Hornik, M. Stinchcombe, and H. White, "Multilayer feedforward networks are universal approximators," Neural Networks, vol. 2, no. 5, pp. 359-366, 1989.

[19] D. T. Pham and X. Liu, Neural Networks for Identification, Prediction and Control, Springer, New York, NY, USA, 1995. 

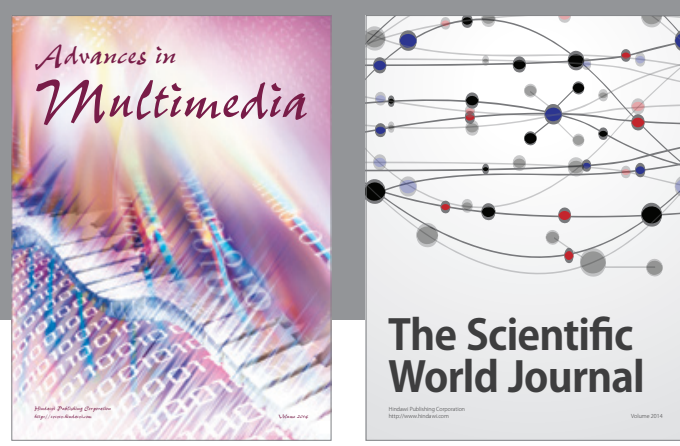

The Scientific World Journal
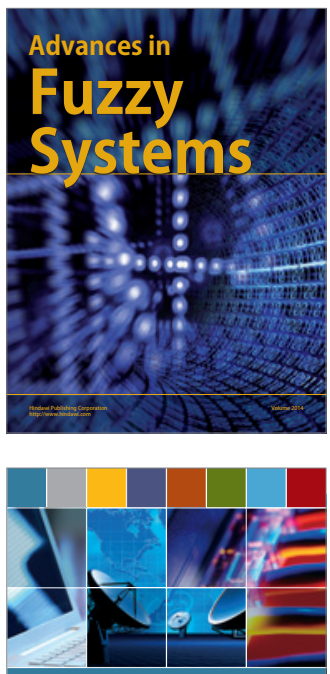

Computer Networks and Communications
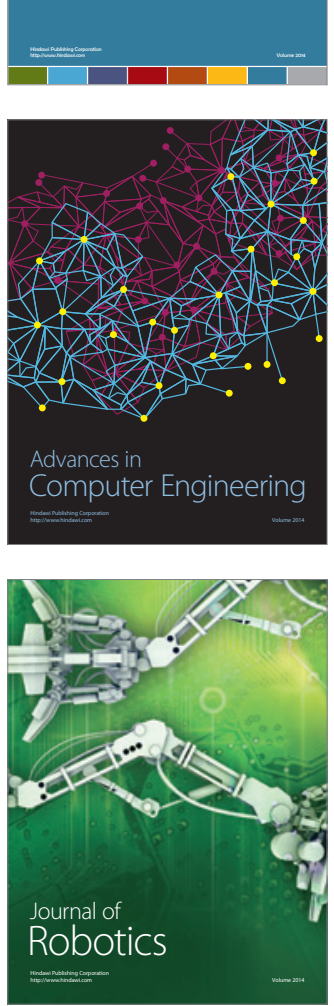
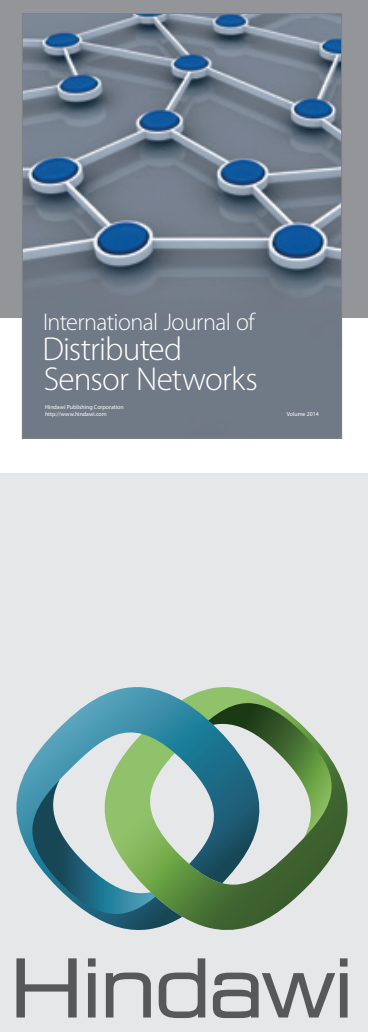

Submit your manuscripts at

http://www.hindawi.com
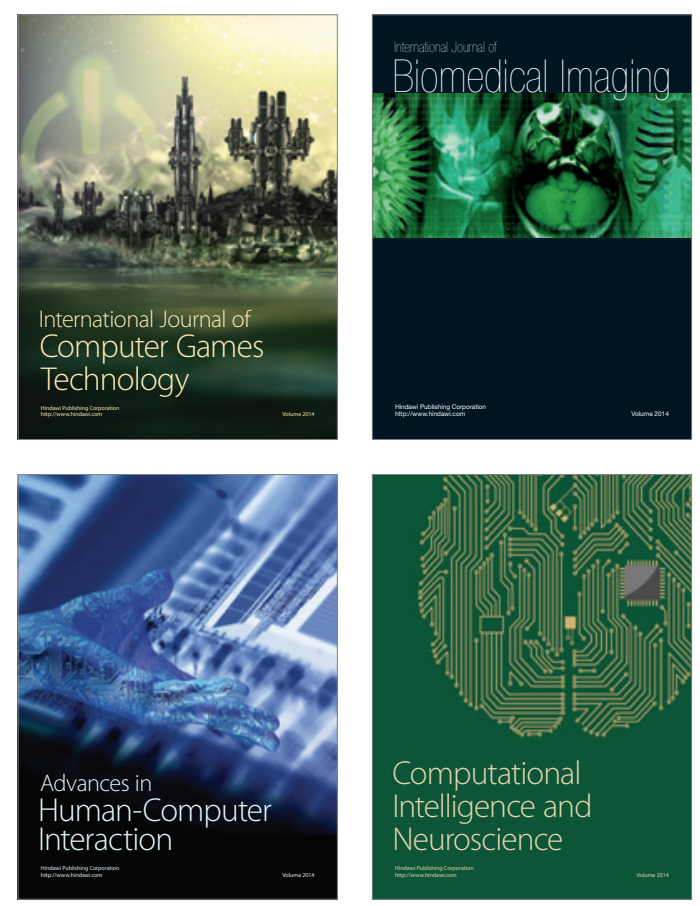
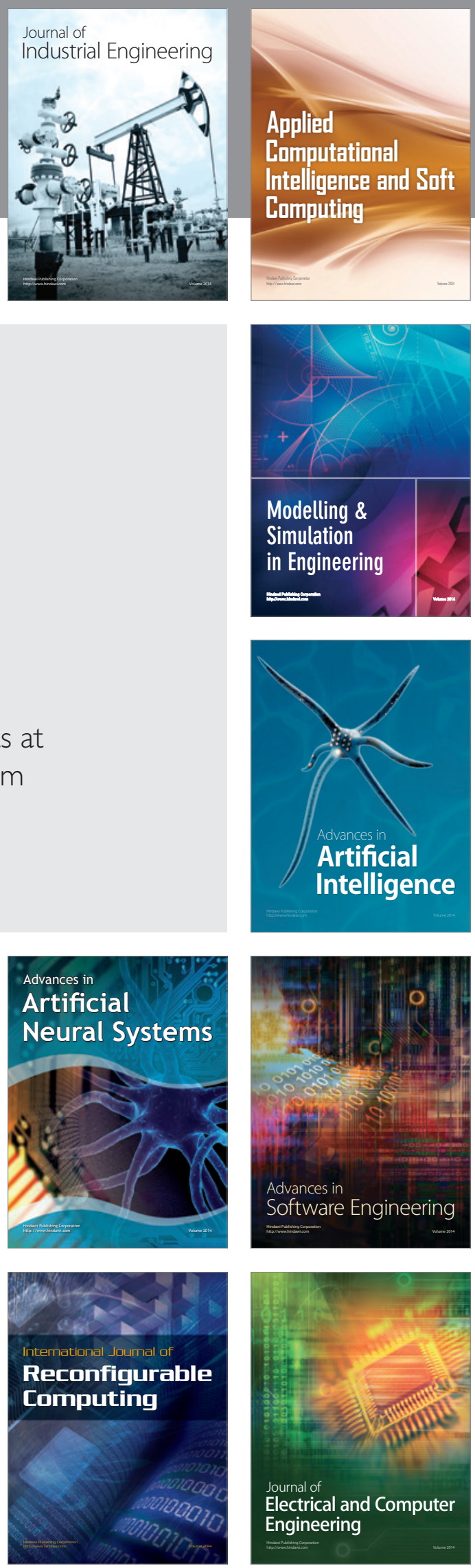